\title{
Interaction of 1,1-Diamino-2,2-Dinitroethylene with Aluminum and Gallium Admixture - DFT Treatment
}

\section{Lemi Türker}

Department of Chemistry, Middle East Technical University, Üniversiteler, Eskişehir Yolu No: 1, 06800 Çankaya/Ankara, Turkey; e-mail: 1turker@gmail.com; lturker@metu.edu.tr

\begin{abstract}
Interaction of 1,1-diamino-2,2-dinitroethylene with $\mathrm{nAl}+\mathrm{mGa}(\mathrm{n}, \mathrm{m}: 1,2)$ admixture has been investigated within the constraints of density functional theory at the level of UB3LYP/6-311++G(d,p). Various multiplicity states arise for the composites due to the open-shell ground state electronic configurations of $\mathrm{Al}$ and $\mathrm{Ga}$ atoms. The composites are electronically stable, thermodynamically exothermic and have favorable Gibbs' free energy of formation values. Various quantum chemical properties have been obtained and discussed. The calculated UV-VIS spectra indicate that some of the composites are infrared absorbing systems beyond $700 \mathrm{~nm}$.
\end{abstract}

\section{Introduction}

FOX-7, chemically 1,1-diamino-2,2-dinitroethylene and abbreviated as DADE or DADNE, is an insensitive high explosive [1]. Swedish Defense Research Agency (FOI) members synthesized it in 1998 [2, 3]. Afterwards, many researchers have investigated its explosive potential thoroughly [4-18]. An alternative route to FOX-7 is based on the nitration of 4,6-dihydroxy-2-methylpyrimidine and then hydrolysis [19].

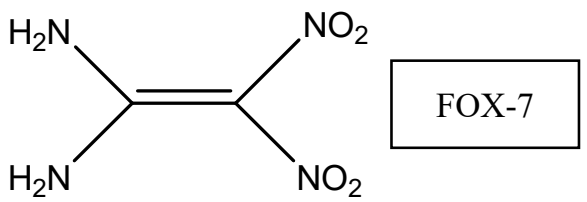

Received: October 15, 2020; Accepted: November 19, 2020

Keywords and phrases: 1,1-diamino-2,2-dinitroethylene, FOX-7, DADNE, aluminum, gallium, DFT.

Copyright (C) 2021 Lemi Türker. This is an open access article distributed under the Creative Commons Attribution License, which permits unrestricted use, distribution, and reproduction in any medium, provided the original work is properly cited. 
FOX-7 is a novel insensitive high-energy material exhibiting good thermal stability and low sensitivity. Moreover, it possesses excellent application performance among the solid propellants and insensitive ammunitions. In spite of the fact that it has a simple molecular composition and structure, it exhibits abundant chemical reactivity such as coordination reactions, nucleophilic substitutions, acetylate reactions, oxidation and reduction reactions, electrophilic addition reactions etc., [20, 21]. FOX-7 is much less sensitive than RDX (in terms of impact, friction, and electrostatic discharge sensitivities) [22] although RDX or HMX possesses the same $\mathrm{C} / \mathrm{H} / \mathrm{N} / \mathrm{O}$ ratio as FOX-7 has. FOX-7 has been shown to possess many polymorphic forms of such as $\alpha$ - and $\beta$-forms. Of which the $\alpha$-form reversibly turns into $\beta$-form by heat treatment $[23,24]$. However, at higher temperature, an irreversible conversion of $\beta$-polymorph occurs to yield $\gamma$-phase which decomposes at $504 \mathrm{~K}$ [23]. The decomposition process has been extensively searched [25]. Also, the effect of high pressure on the crystal structure of FOX-7 has been studied [26]. The last couple of decades have evidenced several FOX-7 based propellant formulations which have been developed in order to obtain several propellant compositions having a minimum or reduced smoke production [27].

Recently, some novel derivatives of FOX-7 and their properties as energetic materials have been reported [28, 29]. Some aluminized FOX-7 compositions were reported $[30,31]$. Also some molecular orbital calculations were reported on aluminized FOX-7 [32-35].

Aluminum has been used for several decades in certain $\mathrm{TNT} / \mathrm{NH}_{4} \mathrm{NO}_{3}$ commercial explosives (e.g., the Ammonals) as an additional fuel to increase the power and gas volume. Aluminized military explosives appeared as prominent charges in II World War [36].

In the present article composites which are composed of 1,1-diamino-2,2dinitroethylene, aluminum and gallium have been considered computationally.

\section{Method of Calculation}

In the present study, the initial structural optimizations of all the structures leading to energy minima have been achieved by using MM2 method followed by semi-empirical PM3 self-consistent fields molecular orbital (SCF MO) method [37, 38] at the restricted level $[39,40]$. Subsequent optimizations were achieved at Hartree-Fock level using various basis sets. Then, the structural optimizations were managed within the 
framework of density functional theory (DFT) $[41,42]$ at the level of UB3LYP/6$311++\mathrm{G}(\mathrm{d}, \mathrm{p})[40,43]$. The exchange term of B3LYP consists of hybrid Hartree-Fock and local spin density (LSD) exchange functions with Becke's gradient correlation to LSD exchange [41, 44]. The correlation term of B3LYP consists of the Vosko, Wilk, Nusair (VWN3) local correlation functional [45] and Lee, Yang, Parr (LYP) correlation correction functional [46]. Also, the vibrational analyses have been done. The total electronic energies are corrected for the zero point vibrational energy (ZPE). The normal mode analysis for each structure yielded no imaginary frequencies for the $3 N-6$ vibrational degrees of freedom, where $N$ is the number of atoms in the system. This indicates that the structure of each molecule corresponds to at least a local minimum on the potential energy surface. All these calculations were done by using the Spartan 06 package program [47].

\section{Results and Discussion}

Aluminum and gallium have the ground state electronic configurations of $1 s^{2} 2 s^{2} 2 p^{6} 3 s^{2} 3 p^{1}$ and $1 s^{2} 2 s^{2} 2 p^{6} 3 s^{2} 3 p^{6} 3 d^{10} 4 s^{1}$, respectively [48]. Certain metals are added in to composition of explosives for certain purposes. One of the most important one is to increase the heat produced in the explosion process. Those metals are oxidized, such as aluminum forms $\mathrm{Al}_{2} \mathrm{O}_{3}$ which is accompanied by the liberation of $1669 \mathrm{~kJ} / \mathrm{mol}$ energy [49]. Gallium may produce $\mathrm{Ga}_{2} \mathrm{O}$ and $\mathrm{Ga}_{2} \mathrm{O}_{3}$ which yield heat energy of 340 and 1079 $\mathrm{kJ} / \mathrm{mol}$, respectively [49]. The interaction of gallium alone with FOX-7 has been published [50]. It has been found that gallium atom does not initiate any bond rupture. However, certain distortions in bond lengths and angles occur.

In the present study, interaction of 1,1-diamino-2,2-dinitroethylene with aluminum and gallium admixture has been investigated (Table 1). Since, both of aluminum and gallium are open-shell systems in their ground states, various multiplicity possibilities arise for the composites considered which are listed in Table 1.

Figure 1 shows the optimized structures of the composites as well as the direction of the dipole moment vectors. Note that the dipole moment vectors orient themselves as highly depending on the multiplicity. Since both of aluminum and gallium atoms have an unpaired electron, the total spin of the set of those metals indirectly affects the energy of the structures, thus the geometry is subjected to variation from one composite to the other keeping the number of metal atoms be the same. Note that the conformations of 
Table 1. Composites considered.

Composite

FOX $-7+\mathrm{Al}+\mathrm{Ga}$

$\mathrm{FOX}-7+\mathrm{Al}+\mathrm{Ga}$

$\mathrm{FOX}-7+\mathrm{Al}+2 \mathrm{Ga}$

$\mathrm{FOX}-7+\mathrm{Al}+2 \mathrm{Ga}$

$\mathrm{FOX}-7+2 \mathrm{Al}+\mathrm{Ga}$

FOX $-7+2 \mathrm{Al}+\mathrm{Ga}$

Formula

Al. $\mathrm{C}_{2} \mathrm{H}_{4} \mathrm{~N}_{4} \mathrm{O}_{4}$. Ga

Al. $\mathrm{C}_{2} \mathrm{H}_{4} \mathrm{~N}_{4} \mathrm{O}_{4}$. $\mathrm{Ga}$

Al. $\mathrm{C}_{2} \mathrm{H}_{4} \mathrm{~N}_{4} \mathrm{O}_{4} \cdot 2 \mathrm{Ga}$

Al. $\mathrm{C}_{2} \mathrm{H}_{4} \mathrm{~N}_{4} \mathrm{O}_{4} \cdot 2 \mathrm{Ga}$

2Al. $\mathrm{C}_{2} \mathrm{H}_{4} \mathrm{~N}_{4} \mathrm{O}_{4} \cdot \mathrm{Ga}$

2Al. $\mathrm{C}_{2} \mathrm{H}_{4} \mathrm{~N}_{4} \mathrm{O}_{4} \cdot \mathrm{Ga}$
Abbreviation

As

At

$\mathrm{Bd}$

$\mathrm{Bq}$

$\mathrm{Cd}$

$\mathrm{Cq}$
Multiplicity

Singlet

Triplet

Doublet

Quartet

Doublet

Quartet

$\mathrm{NO}_{2}$ and $\mathrm{NH}_{2}$ groups exhibit variations depending on the multiplicity of the systems considered which should affect the $\pi$-conjugation and the pull-push character of the parent DADNE structure, thus various properties of the composites considered are to be affected.

Table 2 shows some energies of the composites considered where $\mathrm{E}, \mathrm{ZPE}$ and $\mathrm{E}_{\mathrm{C}}$ stand for the total electronic energy, zero point vibrational energy and the corrected total electronic energy values, respectively. As seen in the table for DADNE + Al + Ga case, the singlet is more stable than the triplet case whereas for the others the quartet state is more stable than the respective doublet case.

Table 2. Some energies of the composites considered.

\begin{tabular}{cccc} 
Composite & $\mathbf{E}$ & $\mathbf{Z P E}$ & $\mathbf{E}_{\mathbf{C}}$ \\
\hline As & -7261908.44 & 241.98 & -7261666.46 \\
At & -7261625.22 & 237.92 & -7261387.30 \\
Bd & -12315491.70 & 238.66 & -12315253.04 \\
Bq & -12315533.22 & 239.32 & -12315293.90 \\
Cd & -7898209.22 & 242.05 & -7897967.17 \\
Cq & -7898323.76 & 238.45 & -7898085.31 \\
\hline
\end{tabular}

Energies in $\mathrm{kJ} / \mathrm{mol}$. 

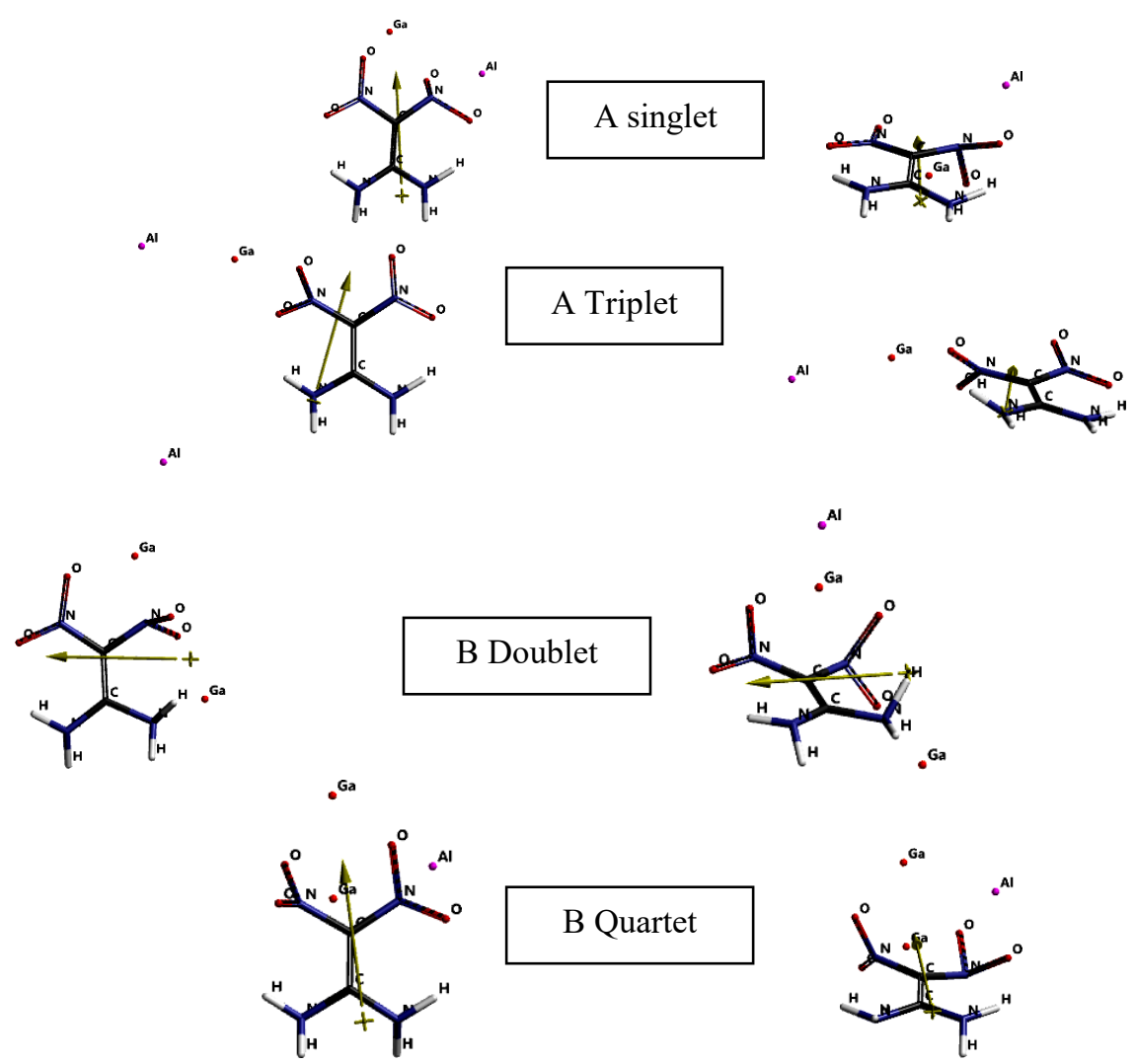

$0^{A 1} \quad .^{A I}$
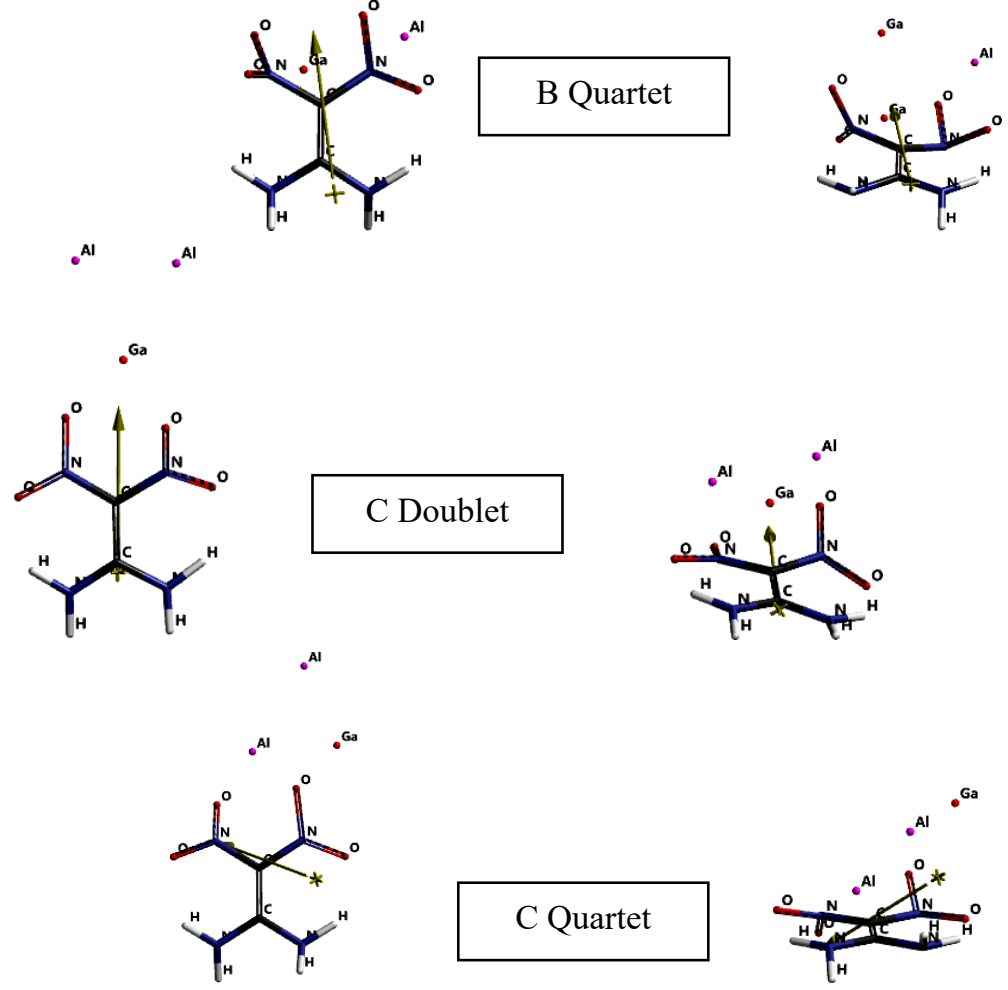

Figure 1. Optimized structures of the composites considered (two different angle of views). 
Table 3 shows some of the standard state thermodynamic properties of the composites presently focus of investigation. The singlet state of $\mathrm{DADNE}+\mathrm{Al}+\mathrm{Ga}$ is more exothermic than its triplet case. For the other composites the quartet state is more exothermic than the respective doublet state. The same occurrences are also true for Gibbs' free energy values at the standard state. So, composite - As is more favorable over At. The composites $\mathrm{Bq}$ and $\mathrm{Cq}$ are more likely to occur than $\mathrm{Bd}$ and $\mathrm{Cd}$.

Table 3. Some thermodynamic properties of the composites considered.

\begin{tabular}{cccc}
\hline Composite & $\mathbf{H}^{\mathbf{0}}$ & $\mathbf{S}^{\mathbf{o}}(\mathbf{J} / \mathbf{m o l} \mathbf{.})$ & $\mathbf{G}^{\mathbf{0}}$ \\
\hline As & -7261702.483 & 431.10 & -7261831.003 \\
At & -7261421.657 & 448.28 & -7261555.296 \\
Bd & -12315331.27 & 469.62 & -12315471.290 \\
Bq & -12315372.28 & 466.29 & -12315511.301 \\
Cd & -7898004.562 & 465.23 & -7898143.269 \\
Cq & -7898122.264 & 468.49 & -7898261.942 \\
\hline
\end{tabular}

Energies in $\mathrm{kJ} / \mathrm{mol}$.

Some selected properties of the composites are shown in Table 4, where PSA stands for polar surface are and the ovality is define as, QSAR descriptor area/[4 $\pi$ (3volume/ $4 \pi)^{2 / 3}$ ] [47]. As seen in the table, $\mathrm{Cq}$ and $\mathrm{Cd}$ are characterized with the lowest and the highest dipole moments, respectively. Also, in the case of DADNE $+\mathrm{Al}+2 \mathrm{Ga}$ composites, the dipole moment of the doublet is greater than the quartet. Whereas for DADNE+Al+ Ga composite, the triplet case has a greater dipole moment than the singlet. Obviously all these outcomes arise from the vectorial sum of bond dipoles which are inherently affected by the charge distributions. Figure 2 displays electrostatic potential charges (ESP) on the atoms of the composites considered. Note that the ESP charges are obtained by the program based on a numerical method that generates charges that reproduce the electrostatic potential field from the entire wavefunction [47]. In each case, except the quartet of composite-C (DADNE $+2 \mathrm{Al}+\mathrm{Ga})$ the $\mathrm{Ga}$ atom acquires more positive charge than the $\mathrm{Al}$ atom. Note that the first ionization potentials of aluminum and gallium are 5.96 and $5.97 \mathrm{eV}$, respectively [48]. The second and third ionization potentials of aluminum are less than the respective values of gallium [48]. 
Table 4. Some properties of the composites.

\begin{tabular}{cccc}
\hline Composite & PSA $\left(\AA^{\mathbf{2}}\right)$ & Ovality & Dipole (debye) \\
\hline As & 95.415 & 1.33 & 6.30 \\
At & 107.899 & 1.39 & 7.39 \\
$\mathrm{Bd}$ & 98.743 & 1.38 & 4.00 \\
$\mathrm{~Bq}$ & 94.123 & 1.33 & 2.96 \\
$\mathrm{Cd}$ & 103.342 & 1.38 & 8.01 \\
$\mathrm{Cq}$ & 97.999 & 1.38 & 2.50 \\
\hline
\end{tabular}

Figure 3 displays the electrostatic potential maps of the composites considered where $\mathrm{red} /$ reddish and blue/green regions stand for negative and positive potential fields, respectively.

Figure 4 shows some of the molecular orbital energy levels of the composites. Note that for all the composites, except composite-As which stands for a closed shell structure, $\alpha$ - and $\beta$-type molecular orbitals emerge. In the figure they are represented by notation as a- and b-type molecular orbital energy levels. Each system has its own peculiarities beyond any generalizations.

Table 5 shows the HOMO, LUMO energies and the interfrontier molecular orbital energy gap values $\left(\Delta \varepsilon=\varepsilon_{\mathrm{LUMO}}-\varepsilon_{\mathrm{HOMO}}\right)$. The order of $\mathrm{HOMO}$ energies is $\mathrm{As}<\mathrm{Cq}<\mathrm{Cd}<\mathrm{Bd}<\mathrm{At}<\mathrm{Bq}$. As for the LUMO energies, the order is $\mathrm{Bd}<\mathrm{Cd}<\mathrm{Cq}<\mathrm{At}<\mathrm{As}$ $<$ Bq. Consequently, the order of $\Delta \varepsilon$ values become $\mathrm{As}>\mathrm{Bq}>\mathrm{Cq}>\mathrm{Cd}>\mathrm{At}>\mathrm{Bd}$. Note that in each isomeric composite, with the exception of A-types, the higher multiplicity owner isomer has greater $\Delta \varepsilon$ value.

Figures 5-7 depict the UV-VIS (time dependent DFT) spectra of the composites. Note that $\mathrm{Cd}$, (DADNE+2Al+Ga) does not have any absorption in the range of 200-700 $\mathrm{nm}$. The spectrum of composite-At exhibits some bathochromic effect as compared to its singlet case As. On the other hand, composite-Bq possesses highly expanded (in both directions) spectrum as compared to composite-Bd. It shows absorption beyond $700 \mathrm{~nm}$ as composite-Cq. Thus, those composites should be infrared absorbing systems, importing some peculiar electronic characteristics to the properties of them. 

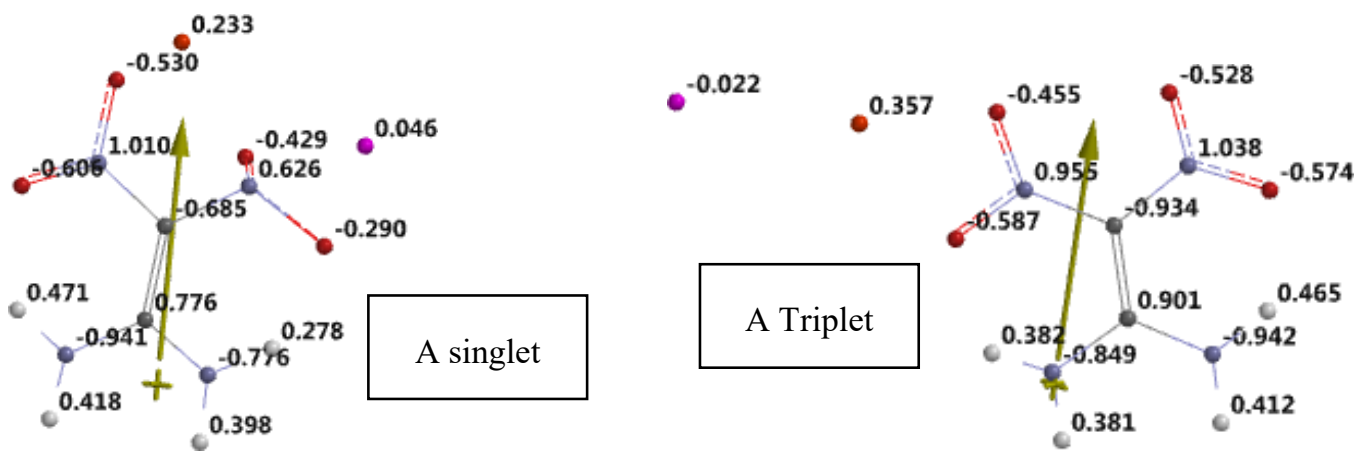

$$
0.196
$$
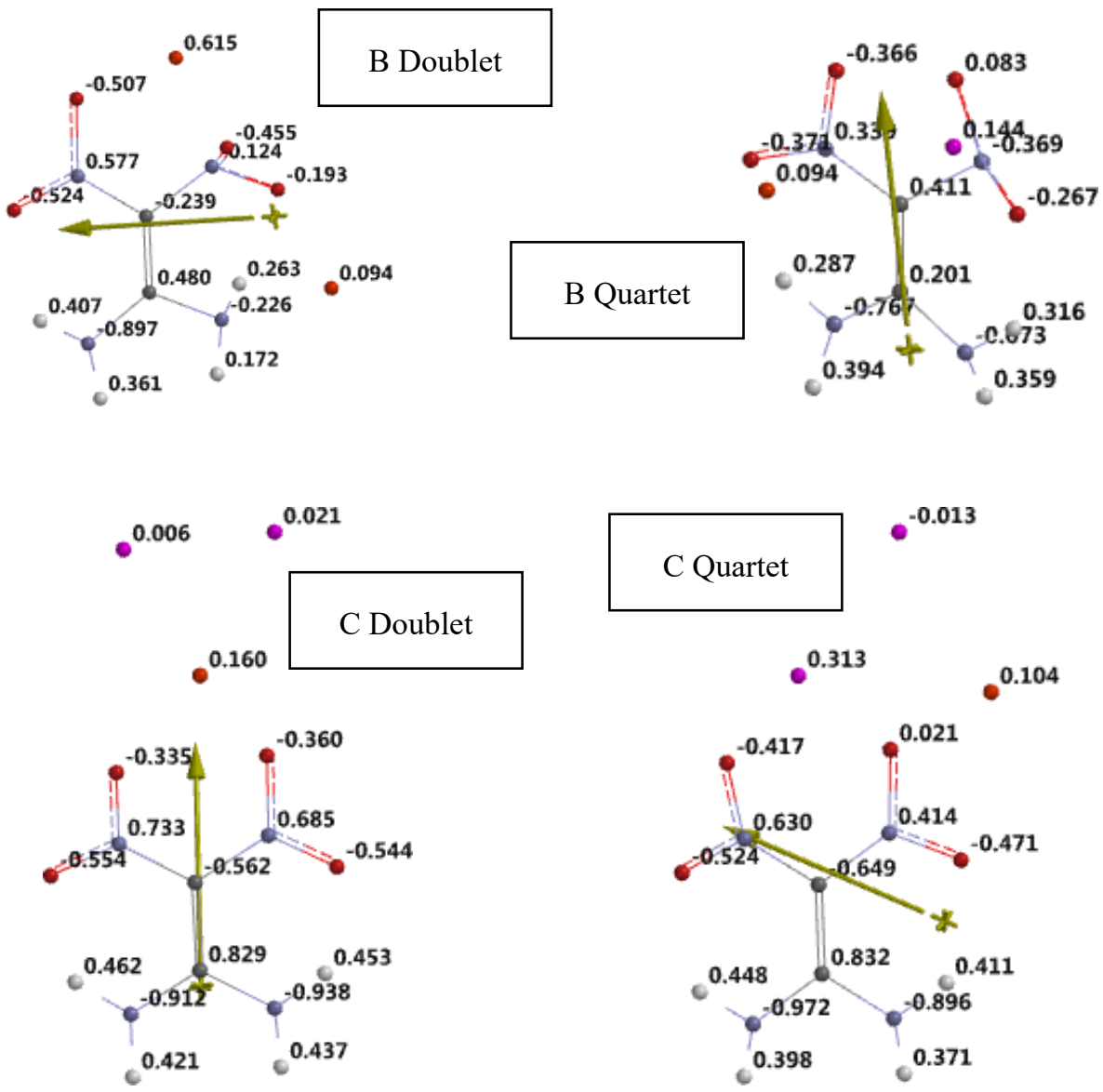

Figure 2. Electrostatic charges on the atoms of the composites considered. 

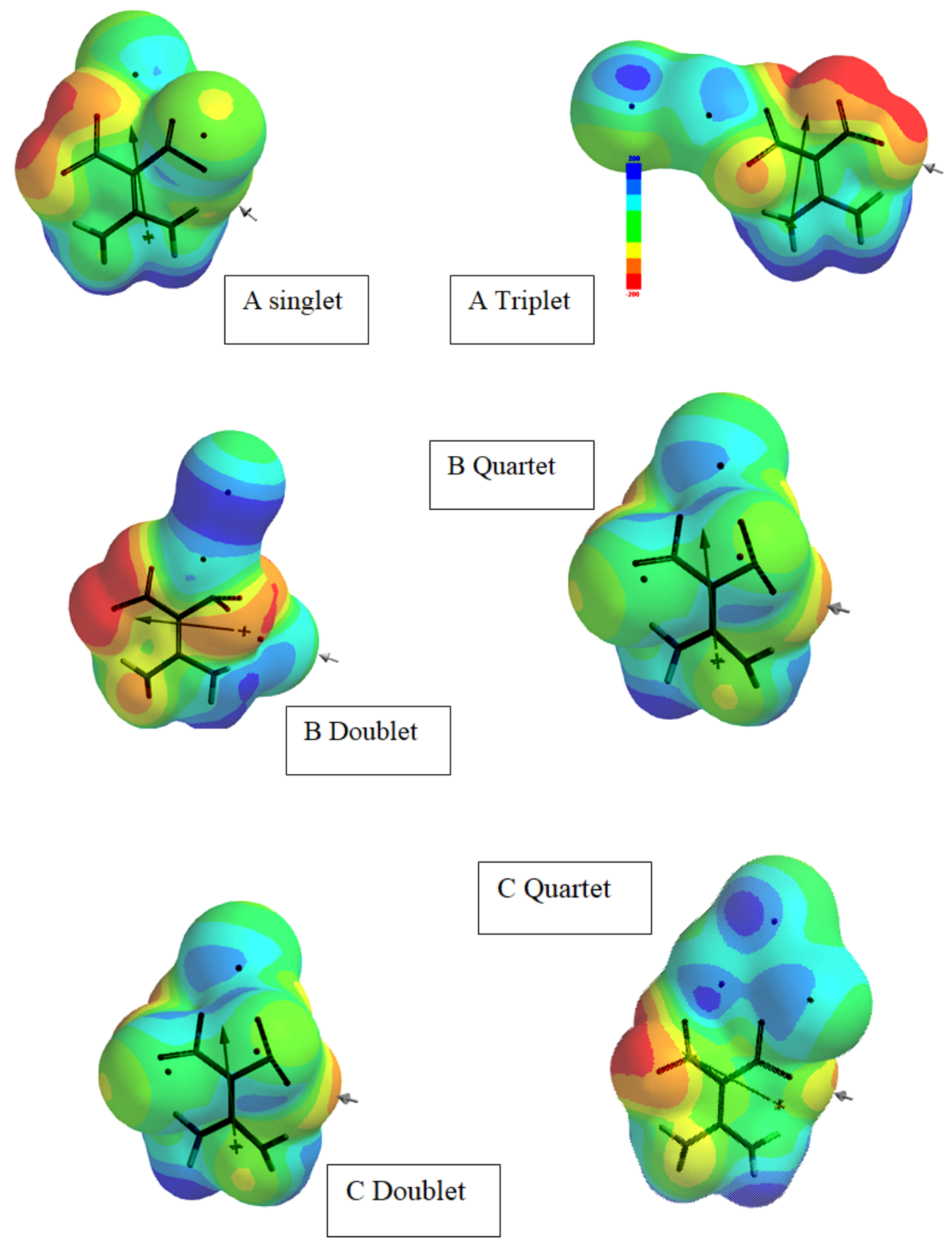

Figure 3. Electrostatic potential maps of the composites considered. 

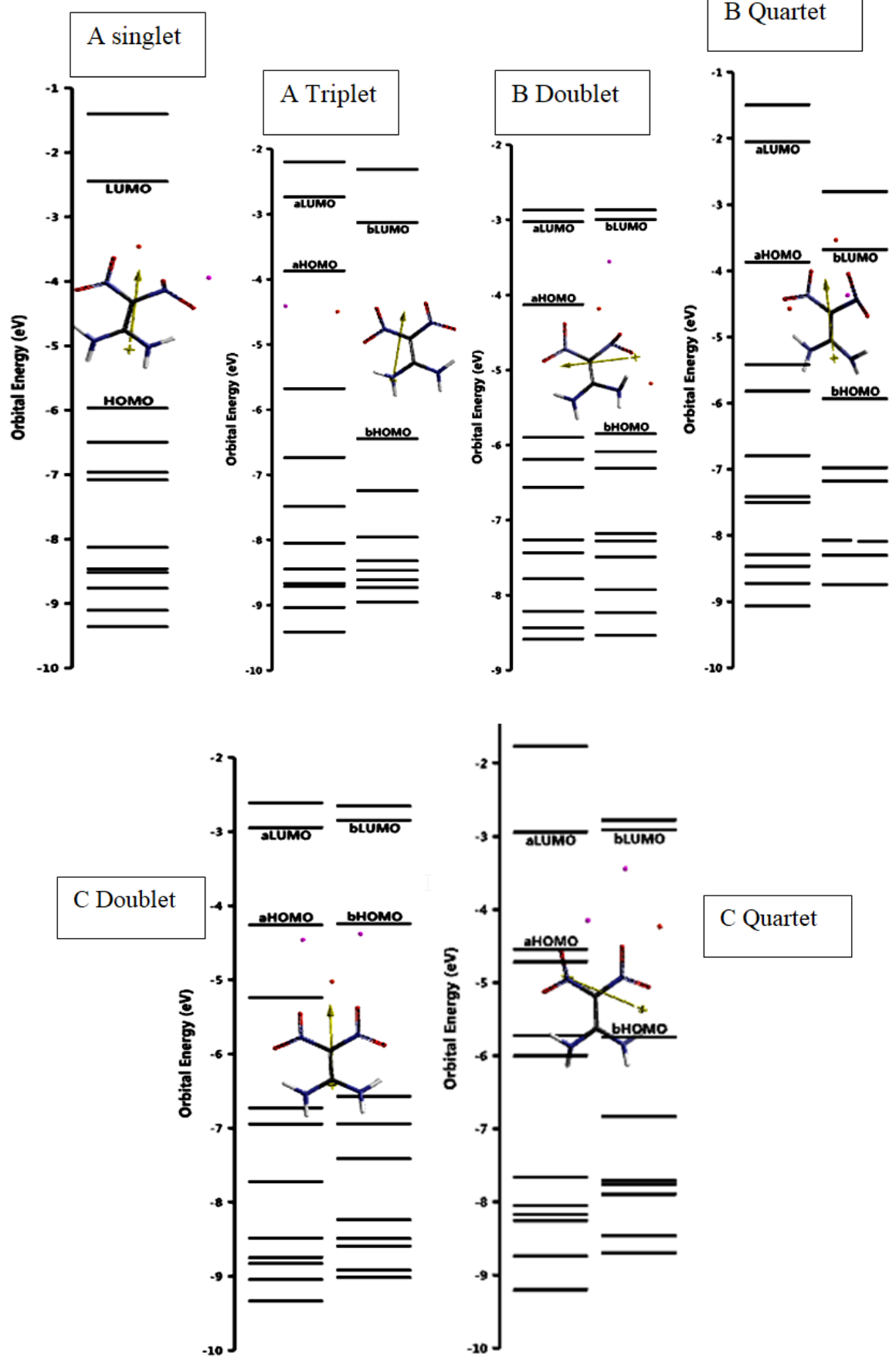

B Quartet 
Table 5. The HOMO, LUMO energies and $\Delta \varepsilon$ values of the composites considered.

\begin{tabular}{cccc}
\hline Composite & HOMO & LUMO & $\Delta \varepsilon$ \\
\hline As & -575.62 & -236.13 & 339.49 \\
At & -373.48 & -263.68 & 109.80 \\
$\mathrm{Bd}$ & -398.28 & -291.45 & 106.83 \\
$\mathrm{~Bq}$ & -373.37 & -197.57 & 175.80 \\
$\mathrm{Cd}$ & -410.52 & -284.18 & 126.34 \\
$\mathrm{Cq}$ & -438.58 & -283.54 & 155.04 \\
\hline
\end{tabular}

Energies in $\mathrm{kJ} / \mathrm{mol}$.
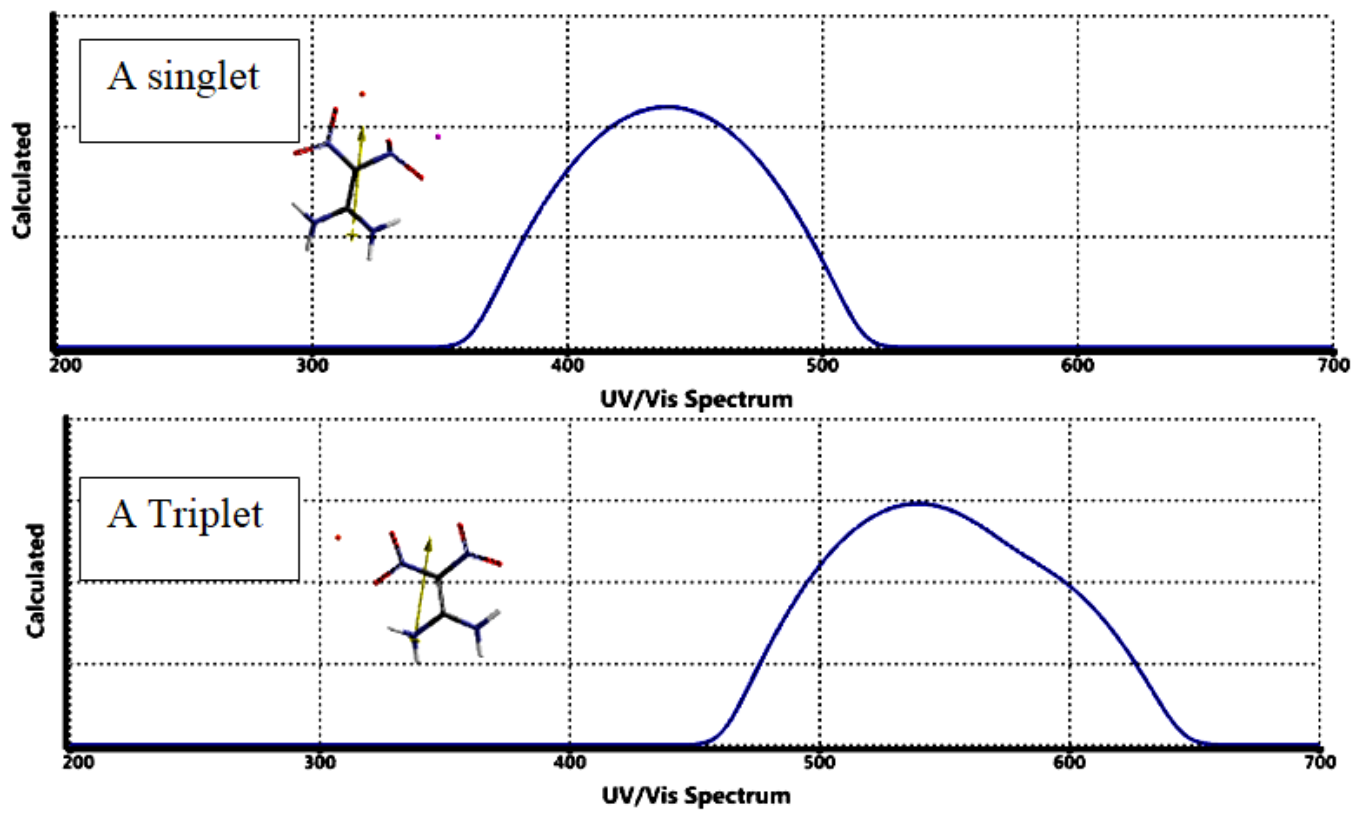

Figure 5. UV-VIS spectra of $\mathrm{DADNE}+\mathrm{Al}+\mathrm{Ga}$ composites. 

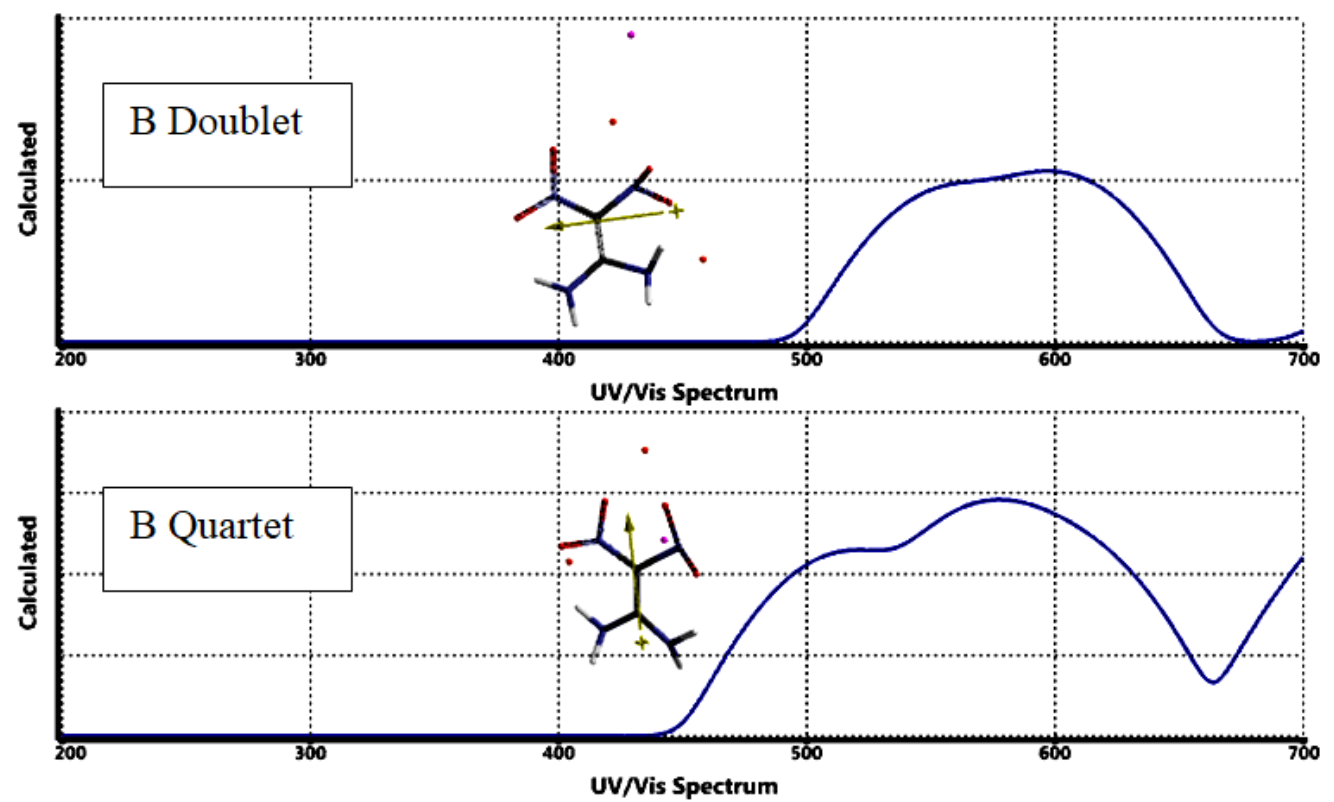

Figure 6. UV-VIS spectra of DADNE+Al+2Ga composites.

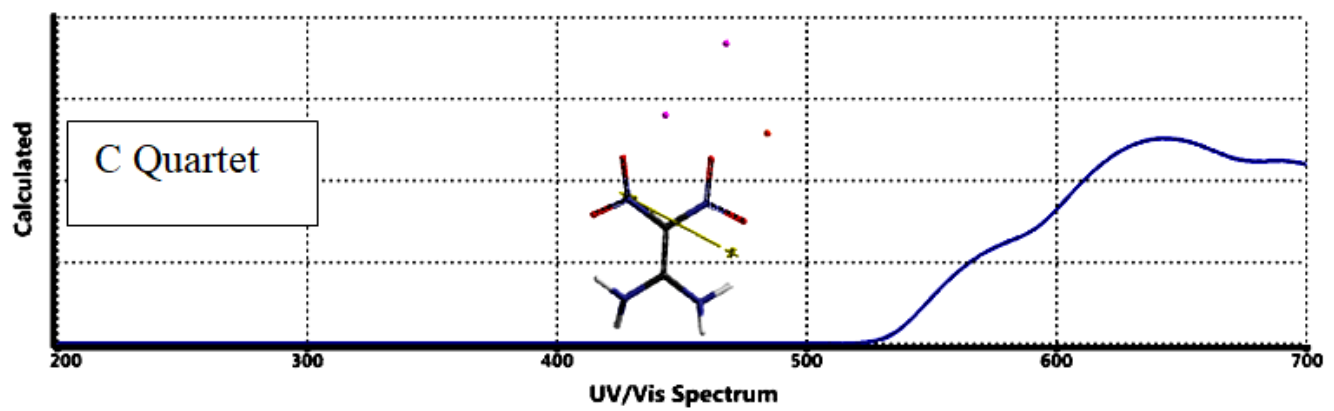

Figure 7. UV-VIS spectra of DADNE $+2 \mathrm{Al}+\mathrm{Ga}$ composite.

Note that the impact sensitivity of explosives are related to the interfrontier molecular orbital energy gap values. That is narrower the gap, the explosive becomes more sensitive to an impact stimulus [51, 52]. Thus, composite-Bd and then At should be the most sensitive two successive members of the composite set.

\section{Conclusion}

The present DFT treatment, within the restrictions of the theory and the applied basis 
set, indicate that aluminum and gallium admixtures are compatible with DADNE molecule causing no bond cleavages (for DADNE $+\mathrm{nAl}+\mathrm{mGa}(\mathrm{n}, \mathrm{m}: 1,2)$ ) but some conformational changes occur. However, those variations influence the $\pi$-conjugation of DADNE, thus various quantum chemical, physicochemical and ballistic properties of the composites considered vary depending on the composition and the multiplicity of the system. Obviously, the bulk compositions could be controlled by the number of moles of the components. However, the local compositions are dictated by the energetics of the local systems. So, locally, systems having different multiplicities may occur.

\section{References}

[1] J.P. Agrawal, High Energy Materials, Weinheim: Wiley-VCH, 2010. https://doi.org/10.1002/9783527628803

[2] P. Politzer and J.S. Murray, Energetic Materials, Part 1, Amsterdam: Elsevier, 2003.

[3] I.J. Lochert, FOX-7 - A new insensitive explosive FOX-7, DSTO Aeronautical and Maritime Research Laboratory 506 Lorimer St, Fishermans Bend, Victoria 3207 Australia 2001, AR-012-065, November 2001.

[4] N. V. Latypov, J. Bergman, A. Langlet, U. Wellmar and U. Bemm, Synthesis and reactions of 1,1-diamino-2,2-dinitroethylene, Tetrahedron 54 (1998), 11525-11536. https://doi.org/10.1016/S0040-4020(98)00673-5

[5] U. Bemm and H. Östmark, 1,1-diamino-2,2-dinitroethylene: a novel energetic material with infinite layers in two dimensions, Acta Cryst. C54 (1998), 1997-1999. https://doi.org/10.1107/S0108270198007987

[6] N.V. Latypov, A. Langlet and U. Wellmar, New chemical compound suitable for use as an explosive, intermediate and method for preparing the compound, World Patent WO99/03818, 1999.

[7] H. Östmark, H. Bergman, U. Bemm, P. Goede, E. Holmgren, M. Johansson, A. Langlet, N.V. Latypov, A. Pettersson, M.L. Pettersson, N. Wingborg, C. Vörde, H. Stenmark, L. Karlsson and M. Hihkiö, 2,2-Dinitroethene-1,1-diamine (FOX-7) - properties, analysis and scale-up, 32 ${ }^{\text {nd }}$ International Annual Conference of ICT on Energetic MaterialsIgnition, Combustion and Detonation, Karlsruhe, Germany, 2001.

[8] H. Östmark, A. Langlet, H. Bergman, N. Wingborg, U. Wellmar and U. Bemm, FOX-7 a new explosive with low sensitivity and high performance, The $11^{\text {th }}$ International Detonation Symposium, Colorado, USA, 1998. 
[9] H. Bergman, H. Ostmark, A. Pettersson, M.L. Petterson, U. Bemm and M. Hihkio, Some initial properties and thermal stability of FOX-7, Insensitive Munitions and Energetic Materials Symposium (NDIA), Tampa, Florida, USA, 1999.

[10] W. A. Trzciński and A. Belaada, 1,1-Diamino-2,2-dinitroethene (DADNE, FOX-7) Properties and formulations (a review), Central European Journal of Energetic Materials 13(2) (2016), 527-544. https://doi.org/10.22211/cejem/65000

[11] B. Janzon, H. Bergman, C. Eldsater, C. Lamnevik and H. Ostmark, FOX-7 - A novel, high performance, low vulnerability high explosive for warhead applications, $20^{\text {th }}$ Int. Symp. Ballistics, Orlando, Florida, USA, September 23-27, 2002.

[12] Y.N. Matyushin, G.T. Afanas'ev, V.P. Lebedev, M.N. Mahov and V.I. Pepekin, TATB and FOX-7: Thermochemistry, performance, detonability, sensitivity, $34^{\text {th }}$ Int. Annu. Conf. ICT, Karlsruhe, Germany, June 24-27, 2003.

[13] A.J. Bellamy, N.V. Latypov and P. Goede, Studies on the nitration of new potential precursors for FOX-7, New Trends Res. Energ. Mater. Proc. Semin. $7^{\text {th }}$, Pardubice, Czech Republic, April 20-22, 2004.

[14] S. Cudziło, Z. Chyłek and R. Diduszko, Crystallization and characterization of 1,1diamino-2,2-dinitroethene (DADNE), 36 ${ }^{\text {th }}$ Int. Annu. Conf. ICT, Karlsruhe, Germany, June 28-July 1, 2005.

[15] W.A. Trzciński, S. Cudziło, Z. Chyłek and L. Szymańczyk, Investigation of sensitivity and detonation properties of FOX-7, $37^{\text {th }}$ Int. Annu. Conf. ICT, Karlsruhe, Germany, June 27-30, 2006.

[16] M. Anniyappan, M.B. Talawar, G.M. Gore, S. Venugopalan and B.R. Gandhe, Synthesis, characterization and thermolysis of 1,1-diamino-2,2-dinitroethylene (FOX-7) and its salts, J. Hazard. Mater. B 137 (2006), 812-819.

https://doi.org/10.1016/j.jhazmat.2006.03.034

[17] W. A. Trzciński, S. Cudziło, Z. Chyłek and L. Szymańczyk, Detonation properties of 1,1diamino-2,2-dinitroethene (DADNE), J. Hazard. Mater. 157 (2008), 605-612. https://doi.org/10.1016/j.jhazmat.2008.01.026

[18] V.S. Mishra, S.R. Vadali, R.K. Garg, V.S. Joshi, R.D. Wasnik and S. Asthana, Studies on FOX-7 based melt cast high explosive formulations, Cent. Eur. J. Energ. Mater. 10(4) (2013), 569-580.

[19] N.V. Latypov, M. Johansson, E. Holmgren, E.V. Sizova, V.V. Sizov and A.J. Bellamy, On the synthesis of 1,1-diamino-2,2-dinitroethene (FOX-7) by nitration of 4,6dihydroxy-2-methylpyrimidine, Org. Process Res. Dev. 11 (1) (2007), 56-59. https://doi.org/10.1021/op068010t 
[20] Y. Zhang, Q. Sun, K. Xu, J. Song and F. Zhao, Review on the reactivity of 1,1-diamino2,2-dinitroethylene (FOX-7), Propellants Explos. Pyrotech. 41 (2016), 35-52. https://doi.org/10.1002/prep.201500065

[21] K. Baum, N.V. Nguyen, R. Gilardi, J.L. Flippen-Anderson and C. George, Nitration of 1,1-diamino-2,2-dinitroethylenes, J. Org. Chem. 57 (1992), 3026-3030. https://doi.org/10.1021/jo00037a015

[22] T.M. Klapötke, Chemistry of High-Energy Materials, Berlin: De Gruyter, 2011.

[23] J. Evers, T. M. Klapötke, P. Mayer, G. Oehlinger and J. Welch, $\alpha$ - and $\beta$-FOX-7, polymorphs of a high energy density material, studied by X-ray single crystal and powder investigations in the temperature range from 200 to 423 K, Inorg. Chem. 45 (2006), 4996-5007. https://doi.org/10.1021/ic052150m

[24] M.J. Crawford, J. Evers, M. Göbel, T.M. Klapötke, P. Mayer, G. Oehlinger and J.M. Welch, $\gamma$-FOX-7: Structure of a high energy density material immediately prior to decomposition, Propellants Explos. Pyrotech. 32 (2007), 478-495. https://doi.org/10.1002/prep.200700240.

[25] A. Gindulyte, L. Massa, L. Huang and J. Karle, Proposed mechanism of 1,1-diaminodinitroethylene decomposition: a density functional theory study, J. Phys. Chem. A 103 (1999), 11045-11051. https://doi.org/10.1021/jp991794a

[26] Z.A. Dreger, A.I. Stash, Z.G. Yu, Y.S. Chen, Y. Tao and Y.M. Gupta, High-pressure crystal structures of an insensitive energetic crystal: 1,1-diamino-2,2-dinitroethene, $J$. Phys. Chem. C 120 (2) (2016), 1218-1224. https://doi.org/10.1021/acs.jpcc.5b10644

[27] H. Lips and K. Menke, FOX-7/GAP rocket propellants for a shoulder launched projectile, 27 th International Symposium on Ballistics, Freiburg, Germany: April 22-26, 2013.

[28] T. Zhou, Y. Li, K. Xu, J. Song and F. Zhao, The new role of 1,1-diamino-2,2dinitroethylene (FOX-7): two unexpected reactions, New J. Chem. 41 (2017), 168-176. https://doi.org/10.1039/c6nj03370a

[29] H. Gao and J.M. Shreeve, Recent progress in taming FOX-7 (1,1-diamino-2,2dinitroethene), RSC Adv. 6 (2016), 56271-56277. https://doi.org/10.1039/c6ra12412g

[30] J. Zhao, X.-J. Feng, H.-T. Xu, X. Tian and B. Feng, Shock initiation characteristics of FOX-7 and RDX based aluminized explosive, Huozhayao Xuebao/Chinese Journal of Explosives and Propellants 39(4) (2016), 42-45 and 50.

[31] D.B. Lempert, E.M. Dorofeenko and Y. Shu, Energy potential of solid composite propellants based on 1,1-diamino-2,2-dinitroethylene, Russian Journal of Physical Chemistry B 10(3) (2016), 483-489. https://doi.org/10.1134/S1990793116030258 
[32] C.-C. Ye, F.-Q. Zhao, S.-Y. Xu and X.-H. Ju, Density functional theory studies on adsorption and decomposition mechanism of FOX-7 on Al13 clusters, Canadian Journal of Chemistry 91(12) (2013), 1207-1212. https://doi.org/10.1139/cjc-2013-0334

[33] L. Bian, Y. Shu, J. Xu and L. Wang, Computational investigation on the new high energy density material of aluminum enriched 1,1-diamino-2,2-dinitroethylene, Journal of Molecular Modeling 19(1) (2013), 131-138. https://doi.org/10.1007/s00894-012-1533-x

[34] C. Ye, X. Ju, F. Zhao and S. Xu, Adsorption and decomposition mechanism of 1,1diamino-2,2-dinitroethylene on $\mathrm{Al}(111)$ surface by periodic DFT calculations, Chin. J. Chem. 30(10) (2012), 2539-2548. https://doi.org/10.1002/cjoc.201200470

[35] D.C. Sorescu, J.A. Boatz and D.L. Thompson, First-principles calculations of the adsorption of nitromethane and 1,1-diamino-2,2-dinitroethylene (FOX-7) molecules on the $\mathrm{Al}(111)$ surface, J. Phys. Chem. B 107(34) (2003), 8953-8964. https://doi.org/10.1021/jp030258m

[36] J. Taylor, Solid Propellent and Exothermic Compositions, London: George Newnes Ltd., 1959.

[37] J.J.P Stewart, Optimization of parameters for semiempirical methods I. Method, $J$. Comput. Chem. 10 (1989), 209-220. https://doi.org/10.1002/jcc.540100208

[38] J.J.P Stewart, Optimization of parameters for semi empirical methods II. Application, $J$. Comput. Chem. 10 (1989), 221-264. https://doi.org/10.1002/jcc.540100209

[39] A. R. Leach, Molecular Modeling, Essex: Longman, 1997.

[40] P. Fletcher, Practical Methods of Optimization, New York: Wiley, 1990.

[41] W. Kohn and L. Sham, Self-consistent equations including exchange and correlation effects, Phys. Rev. 140 (1965), A1133-A1138. https://doi.org/10.1103/PhysRev.140.A1133

[42] R. G. Parr and W. Yang, Density Functional Theory of Atoms and Molecules, London: Oxford University Press, 1989.

[43] C.J. Cramer, Essentials of Computational Chemistry, Chichester, West Sussex: Wiley, 2004.

[44] A.D. Becke, Density-functional exchange-energy approximation with correct asymptotic behavior, Phys. Rev. A 38 (1988), 3098-3100. https://doi.org/10.1103/PhysRevA.38.3098

[45] S.H. Vosko, L. Wilk and M. Nusair, Accurate spin-dependent electron liquid correlation energies for local spin density calculations: a critical analysis, Can. J. Phys. 58 (1980), 1200-1211. https://doi.org/10.1139/p80-159 
[46] C. Lee, W. Yang and R.G. Parr, Development of the Colle-Salvetti correlation-energy formula into a functional of the electron density, Phys. Rev. B 37 (1988), 785-789. https://doi.org/10.1103/PhysRevB.37.785

[47] SPARTAN 06, Wavefunction Inc., Irvine CA, USA, 2006.

[48] P.J. Durant and B. Durant, Introduction to Advanced Inorganic Chemistry, London: Longman, 1972.

[49] J.G. Stark and H.G. Wallace, Chemistry Data Book, $2^{\text {nd }}$ ed., London: John Murray Pub., 1982.

[50] L. Türker, Interaction of 1,1-diamino-2,2-dinitroethylene and gallium - DFT treatment, Earthline Journal of Chemical Sciences 2(2) (2019), 271-291.

https://doi.org/10.34198/ejcs.2219.271291

[51] V. Anbu, K.A. Vijayalakshmi, R. Karunathan, A.D. Stephen and P.V. Nidhin, Explosives properties of high energetic trinitrophenyl nitramide molecules: A DFT and AIM analysis, Arabian Journal of Chemistry 12(5) (2019), 621-632.

https://doi.org/10.1016/j.arabjc.2016.09.023

[52] N.R. Badders, C. Wei, A.A. Aldeeb, W.J. Rogers and M.S. Mannan, Predicting the impact sensitivities of polynitro compounds using quantum chemical descriptors, Journal of Energetic Materials 24 (2006), 17-33. https://doi.org/10.1080/07370650500374326 